\title{
AMBIENTE E ESTRATÉGIA: PROPOSIÇÕES PARA MÉDIAS EMPRESAS FAMILIARES
}

ENVIRONMENT AND STRATEGY: PROPOSITIONS FOR

MEDIUM-SIZED FAMILY BUSINESSES

Recebido em 29.08.2016. Aprovado em 26.01.2017

Avaliado pelo sistema double blind review

DOI: http://dx.doi.org/10.12712/rpca.v11i1.807

\section{Ricardo Lebbos Favoreto \\ ricardo.favoreto@hotmail.com \\ Universidade Estadual do Paraná (UNESPAR), Apucarana/PR, BRASIL}

\section{Fernando Antonio Ribeiro Serra}

fernando.serra@hsmeducacao.com.br

Universidade Nove de Julho (UNINOVE), São Paulo/SP, BRASIL

\section{Resumo}

Historicamente, tem-se concebido o ambiente organizacional como elemento fundamental para a compreensão da estratégia. Considerando-se que a pesquisa em estratégia tem-se desenvolvido, em muitos campos, a partir de dados provenientes do lócus da organização de grande porte, esta pesquisa objetiva analisar as ações estratégicas de médias empresas familiares contextualizadas no ambiente específico em que ocorrem. Conduz-se a pesquisa por um estudo multicaso longitudinal qualitativo. Os resultados estabelecem um conjunto de proposições substantivas ambicionadas a explicar as ações estratégicas perpetradas pelas empresas estudadas, relacionandoas a aspectos ambientais. Conclui-se pela relevância de se ponderar o médio porte como categoria específica, uma vez que particularidades ambientais relativas ao porte influenciam as ações estratégicas produzidas pelas empresas.

Palavras-chave: Ambiente Organizacional. Estratégia. Ações Estratégicas. Médio porte. Empresas Familiares.

\section{Abstract}

Business environment has been historically conceived as a fundamental element to comprehend strategy. Taking into account that the research in the strategy field has been in many fields significantly driven on the basis of data derived from cases of large companies, this article aims to analyse strategic actions carried out by medium-sized family businesses contextualized in the specific environment in which they occur. The research is a qualitative longitudinal multicase study. The results establish a set of propositions that aim to explain the strategic actions performed by the companies that we studied, relating them to environmental aspects. We conclude that is relevant to consider the medium size as a specific category, since environmental characteristics related to the size influence the companies' strategic actions.

Keywords: Organizational Environment. Strategy. Strategic Actions. Midsize. Family Businesses. 


\section{Introdução}

Conquanto o enfoque e o nível de análise tenham variado ao longo do tempo, as abordagens teóricas do campo da estratégia modelaram-se, em geral, a partir do estudo de grandes corporações (BARNEY; WRIGHT; KETCHEN, 2001; FAVORETO; AMÂNCIOVIEIRA, 2014), decorrendo daí os construtos medulares do campo. Sendo o capitalismo da era moderna fundado prevalentemente sobre modelos diversos de empresas de propriedade de investidores (HANSMANN, 1996), empresas de capital fechado têm recebido menos atenção na pesquisa em estratégia (FARACI; SHEN, 2012). À organização de pequeno porte são destinados, em contrapartida, os principais esforços de pesquisa do campo do empreendedorismo (HIT'T et al., 2002), tendo, desde a década de 1980, crescido o interesse pelos pequenos negócios como objeto de estudo (ALVAREZ, 2001). O médio porte, por seu turno, parece ainda não ter sedimentado na pesquisa estruturações conceituais específicas, a despeito de, já há algum tempo, reconhecer-se, na teoria organizacional, que diferenças de porte ensejam diferenças de características (BLAU, 1970; BAUM, 2006).

Estudos como o Hidden Champions revelam que, enquanto os modelos vigentes são geralmente fundados em casos de grandes corporações, opera de modo menos chamativo um conjunto de bem sucedidas empresas menores e desconhecidas (SIMON, 2009). Muitas empresas de menor porte criam seus próprios mercados, assim como formas próprias de gestão - supõe-se que amparadas em práticas distintas das usualmente reputadas como as melhores. No Brasil, empresas de médio porte destacam-se nos mais variados setores, a exemplo de tecnologia da informação, construção, máquinas e equipamentos, comércio, prestação de serviços, serviços especializados e indústria química (DELOITTE, 2014), exercendo papel fundamental na economia nacional. Entre 2010 e 2013, receberam pelo sistema do Banco Nacional de Desenvolvimento Econômico e Social (BNDES) mais de R $\$ 13$ bilhões de desembolso por ano (BNDES, 2013), volume superior ao destinado a pequenas empresas, embora sejam estas muito mais numerosas no país.

O médio porte, nos modelos de ciclo de vida organizacional (e.g., QUINN; CAMERON, 1983; KAZANJIAN; DRAZIN, 1990; MOUNT; ZINGER; FORSYTH, 1993), parece restar subentendido como estágio intermediário, percorrido de passagem, em um movimento de progresso em direção ao grande porte. Constatações empíricas levam a deduzir, no entanto, que, por motivos diversos - como comprometimentos estruturais, pressões ambientais ou desejo dos dirigentes -, várias empresas descontinuam o ciclo, estagnando-se no médio porte e aí conservandose com triunfo. $O$ relativo consenso existente na literatura acerca da forma como as organizações se desenvolvem e dos atributos usualmente relacionados a cada etapa de desenvolvimento reforça a relevância de se proceder a distinções de porte, uma vez que, comumente, os estágios modelados são associados, ainda que mediatamente, a questões relacionadas ao porte. É o que se pode inferir, por exemplo, do estudo realizado por Quinn e Cameron (1983), que, partindo da análise de outros modelos, aponta quatro etapas principais, que, não ocasionalmente, se iniciam pela empreendedora e findam com a elaboração e adaptação de estrutura.

O ambiente foi concebido, historicamente, como elemento dos mais relevantes para a compreensão da estratégia. $\mathrm{O}$ ambiente contextualiza a ação estratégica, ora implicando-a, ora sendo por ela alterado. A fugacidade dos estados ambientais fomenta a procura por novas práticas organizacionais (AGUIAR; MELLO JÚNIOR; CASTRO, 2010). Perspectivas diversas já denotaram a relevância do ambiente para a compreensão da estratégia - entre as quais as notórias visão configuracional (MILLER, 1979) e ecologia organizacional (HANNAN; FREEMAN, 1989). Não faltaram, desde então, pesquisas empíricas que relacionaram variáveis ambientais ao desempenho organizacional (e.g., VENKATRAMAN; PRESCOTT, 1990; KOTHA; NAIR, 1995; DAVIS; WALTERS, 2004).

A pesquisa relatada neste artigo objetiva analisar as ações estratégicas de médias empresas familiares contextualizadas no ambiente específico em que ocorrem. Concorrem para o objetivo geral os seguintes objetivos intermediários: (i) detectar as principais ocorrências ambientais acontecidas ao longo da vida organizacional; (ii) identificar as ações utilizadas pelas empresas para gerar ou fazer frente a essas ocorrências; (iii) ordenar elementos proposicionais que expressem padrões de comportamento estratégico do tipo de empresa visado. Análises circunstanciadas pautaram a sondagem dos casos.

Assume-se por princípio que portes distintos podem demandar a admissão de construções teóricas 
distintas, dadas as diferenças decorrentes. Assim, examinando-se casos de médias empresas familiares à luz de um referencial teórico conjugativo de questões referentes ao ambiente e à estratégia, traçam-se proposições substantivas pelas quais se busca explicar as ações perpetradas pelo tipo organizacional visado. A análise longitudinal dos casos permite que se chegue a apontamentos relativamente fiáveis, uma vez que - como próprio da linha metodológica adotada - os padrões sugeridos resultam da apreciação de um conjunto robusto de observações, tanto das ações quanto das variações ambientais sucedidas no período.

\section{Ambiente e estratégia}

O ambiente tem sido historicamente tema recorrente na Teoria Organizacional. Particularmente, no campo da estratégia, a análise ambiental é diligência das mais importantes. Procede-se nesta seção à revisão de questões ligadas ao ambiente organizacional, considerado em referência à gestão estratégica, tomando-se por base a agenda proposta por Pitkethly (2003).

\section{Ambiente estratégico: conceituação}

O conceito de ambiente pressupõe a ideia de fronteira. A distinção entre o que há dentro e fora carrega a noção de um limite distintivo de espaços. É comum na Teoria Organizacional a consideração do espaço externo à organização, a despeito de a realidade muitas vezes não se deixar classificar com clareza, suscitando que a questão das fronteiras organizacionais esteja constantemente sob reflexão (HOLMSTROM; ROBERTS, 1998). Com menor margem à suscitação de dissenso, pode-se conceber o ambiente como o contexto no qual a entidade organizacional existe.

No campo da estratégia, a diferenciação entre o que é interno e o que é externo à organização constitui divisão analítica fundamental, sobre a qual diversas teorias se formataram - entre as quais, algumas das mais marcantes do campo, a exemplo de Coase (1937) e Williamson (1985). Particularmente, destaque-se, como decorrência dessa diferenciação, a evolução da ênfase na estrutura da indústria (PORTER, 1980) para a ênfase nos recursos da firma (WERNERFELT, 1984; BARNEY, 1991) - e, posteriormente, em competências (PRAHALAD; HAMEL, 1990). Perspectivas que priorizam aspectos externos ou internos à organização sustentam-se, respectivamente, sobre uma ou outra ênfase.
Tomando-se por ponto de referência a organização, suas fronteiras é que definem o que reside dentro (espaço no qual seus recursos são organizados) e o que reside fora (o ambiente organizacional). Trata-se, assim, elementarmente, de uma questão de referência.

O que se estipula tratar por ambiente estratégico constitui-se do complexo de condições estratégicas relevantes que envolvem a organização. É possível, na pesquisa, que o ambiente seja seccionado de acordo com a adequação necessária à análise pretendida. $\mathrm{O}$ que é externo pode, assim, por exemplo, estar mais próximo ou menos próximo ou, ainda, ser comum à organização e a um grupo de participantes de mercado mais restrito ou menos restrito. Em razão disso, expressões diversas têm sido utilizadas para designar a extensão do ambiente - como ambiente estratégico comum, ambiente competitivo, ambiente setorial.

Pode-se entender o ambiente como realidade objetiva, posta, ou como realidade subjetiva, construída através da apreciação do sujeito (DESS; ORIGER, 1987; MINTZBERG; AHLSTRAND; LAMPEL, 2000). A denominada Escola Cognitiva assume a ideia de um ambiente que se realiza mais pela visão de quem o concebe do que objetivamente. Percepções sobre o ambiente variam, por exemplo, em função de diferenças nos repertórios individuais (DOWNEY; SLOCUM, 1975). De todo modo, o ambiente é constituído por acontecimentos reais, que dão corpo à realidade, e esta é compreendida como resultado de interpretação.

O que se entende do ambiente é, assim, fruto da interpretação que se lhe dirige - interpretação essa incidida pela limitação da racionalidade do sujeito que a pratica (SIMON, 1976). A maneira como se entende o ambiente influi na maneira como se entende a estratégia. Respostas estratégicas operadas pela organização em face das ocorrências ambientais com as quais se depara são conduzidas, em alguma medida, por dirigentes que comunicam a realidade concreta constatada, de acordo com a interpretação a que a sujeitam. A realidade é, pois, construída na medida em que é comunicada (HINES, 1988). A gestão estratégica passa, elementarmente, pela gestão de sentidos (SMIRCICH; STUBBART, 1985).

A análise do ambiente não é, no entanto, tarefa redundante, como poderia dar a entender a consideração do ambiente como construto social plenamente controlado. É inegável que o ambiente no qual a empresa se situa influencia seu desempenho. 
A relativização descomedida do ambiente pode prejudicar a capacidade de se analisá-lo, ocasionando que se ignorem questões relevantes, às vezes fundamentais, para a compreensão do fenômeno. Como talvez se possa depreender da história relatada por Weick (1995), dos militares perdidos nos Alpes, qualquer mapeamento do ambiente pode ser melhor que nenhum mapeamento.

A habilidade de avaliação da realidade pode ser considerada fundamental para o alcance de sucesso nas escolhas estratégicas. Não que por si o determine, mas a atribuição de algum sentido à pluralidade de eventos que ocorrem a todo momento parece ser fundamental para o estabelecimento de um sistema organizacional, como indica a abordagem de Smirich e Stubbart (1985). Escolhas estratégicas e o consequente posicionamento da empresa resultam de um ajuste de compreensões, sobre as oportunidades vislumbradas no ambiente e os atributos organizacionais internos (CHRISTENSEN et al., 1982). Em referência à Visão Baseada em Recursos, teoria que se volta para os aspectos internos da firma, Raymundo, Contador e Contador (2013, p. 144) colocam: “[...] sugere analisar o ambiente externo para identificar uma indústria (setor) que apresente as oportunidades que possam ser exploradas pelas capacitações da empresa". Como resultado da apreciação do ambiente, projeta-se ter disponível um retrato reflexivo não dos pensamentos do sujeito, mas da realidade, ainda que seja ela apreendida por meio de pensamentos. Cuida-se, prioritariamente, de uma questão de distinção entre meio e fim.

Seja considerado de forma subjetiva ou de forma objetiva, seja tomado como determinante das escolhas estratégicas ou como provedor de contexto para as escolhas, o ambiente é objeto de análises de primordial importância nas decisões estratégicas.

\section{Dimensões e atributos ambientais}

Existem diversas classificações aplicadas ao ambiente organizacional, utilizadas para organizar as análises correspondentes - a exemplo das propostas por Hatch (1997), Scott (2003) e Länsiluoto (2004). A proximidade com a organização pode, por exemplo, orientar a classificação do ambiente em imediato ou em geral (HATCH, 1997). O imediato constitui-se por elementos que afetam e são afetados diretamente pela atividade organizacional, como fornecedores, clientes, sindicatos, agências reguladoras, concorrentes, parceiros; o geral, pelo conjunto de elementos que afetam o ambiente imediato, como cultura, política, economia, normas legais, condições tecnológicas.

De outro modo, pode-se classificar as dimensões ambientais em técnica e institucional (SCOT'T, 2003). A dimensão técnica é constituída por elementos relacionados aos recursos empresariais e a institucional, por elementos culturais e simbólicos que envolvem a organização. Entre os primeiros, destaquem-se competidores, mercados, produtos e serviços. Entre os segundos, elementos cognitivosculturais e normativos que regulam o comportamento organizacional, legitimando-o.

Ainda, pode-se distinguir as dimensões ambientais em ambiente operacional da firma, ambiente competitivo do setor e macroambiente (LÄNSILUOTO, 2004). O primeiro constitui-se por atores ligados corriqueiramente às operações da organização, como consumidores, funcionários, fornecedores e sócios e acionistas; o segundo, por outras organizações que também fazem parte do setor, como concorrentes e potenciais ofertantes de bens substitutos; o terceiro, por questões comuns aos integrantes do setor e incidentes também sobre outros setores, como as relacionadas a aspectos econômicos, políticos, legais, sociais, tecnológicos.

Dentro das dimensões, alguns atributos ajudam a caracterizar o ambiente, permitindo diferir tipos distintos de condições ambientais. Resgatam-se aqui duas relações de atributos.

O ambiente pode ser caracterizado em função dos atributos estabilidade, complexidade, diversidade de mercado e hostilidade (MINTZBERG, 1979). Com relação à estabilidade, o ambiente pode variar de estável a dinâmico; com relação à complexidade, de simples a complexo; com relação à diversidade de mercado, de integrado à diversificado; e com relação à hostilidade, de favorável a hostil. As características que marcam determinado ambiente influenciam o modo como as organizações nele inseridas respondem estrategicamente. Outras categorias (embora denominadas pelos autores de dimensões, não de atributos) são estabelecidas por Dess e Beard (1984): munificência, dinamismo e complexidade. Quanto à primeira, deduz-se haver ambientes mais provedores de recursos que outros; quanto à segunda, haver ambientes nos quais as mudanças são mais previsíveis e outros nos quais elas são menos previsíveis; quanto à terceira, haver ambientes que contêm atividades mais heterogêneas que outros. 
Esses e outros modelos qualificadores presumem que: condições de tempo e espaço importam à análise organizacional; há diferentes estados ambientais; as qualidades variam em continuum; a possibilidade de combinações entre estados variados de atributos diversos torna complexa a análise ambiental. A consideração da diversidade ambiental na pesquisa em estratégia, ainda quando o referencial se ampara em aspectos internos da organização (e.g., MILLER; SHAMSIE, 1996), pode conduzir a resultados mais contextualizados - uma das demandas apontadas para o campo da estratégia (WHIT'TINGTON; PETTIGREW; THOMAZ, 2002). As evidências são reforçadas quando se conduzem estudos longitudinais cujas análises perpassam por diferentes momentos.

\section{Ambiente, mudança e aprendizado}

O ambiente acha-se, de uma forma ou outra, sempre em mudança, o que demanda que as empresas se adaptem. A agudeza das mudanças sociais e econômicas tornou o ambiente muito menos previsível (WITTMANN; LÜBECK; NELSIS, 2013), de difícil compreensão. A habilidade de se adaptar às circunstâncias é uma das habilidades fundamentais de qualquer organização que se pretenda perene. Em outras palavras, a empresa é, a todo momento, confrontada por contingências ambientais, em função das quais é constantemente levada à realização de ajustes em suas estratégias. As estratégias podem ser caracterizadas, pois, em função das características ambientais nas quais são praticadas (MILLER, 1979).

Mudanças ambientais propõem às empresas o desafio da adaptação - ou seja, de entregar ao mercado respostas às novas demandas. Da consideração de que o ambiente está em mutação decorre que a estratégia deve ser entendida como fenômeno não estático, mas animado. Notadamente, as abordagens de estratégias dinâmicas (PORTER, 1991) e capacidades dinâmicas (TEECE; PISANO; SHUEN, 1997) representam bem tal acepção.

As organizações aprendem - ou deveriam aprender - com o ambiente que as circunda. A aprendizagem organizacional exige a contínua revisão da postura dos indivíduos para se aprender a aprender (ARGYRIS; SHÖN, 1978). Estando o ambiente sempre em mutação, é demandado que as organizações se mantenham para ele voltadas, mas ao mesmo tempo desenvolvam internamente a capacidade de aprender. Não se trata apenas da apreensão do que mudou, mas do desenvolvimento de aptidões por meio das quais se possa identificar e responder à mudança.
Em face do ambiente, as organizações mudam ou transformam-se, por meio de aprendizado realizado em nível individual e coletivo, nutrido diretamente da interface mantida entre os membros organizacionais e entre estes e o ambiente. Por diferentes meios, os indivíduos aprendem e desenvolvem-se, e ocasionam consequências em nível grupal e coletivo para a organização (CROSSAN; LANE; WHITE, 1999). As reações às variações ambientais derivam, pois, do aprendizado suscitado na organização, realizado por meio dos seus membros. O processo de absorção é ainda mais relevante quando a organização se acha em ambientes não perenes, nos quais a não percepção ou a percepção tardia do que está ocorrendo leva à redução de competitividade (GONÇALVES; VIEIRA; PEDROZO, 2014).

A construção, ou a desconstrução, e o aperfeiçoamento de rotinas resultam de aprendizagem. $\mathrm{Na}$ teoria evolucionária, rotinas ruins são separadas de rotinas boas por seleção ambiental, porque contribuem para perpetuar aquelas organizações que se estruturam por rotinas mais adequadas, que tendem a gerar melhores desempenhos (NELSON; WINTER, 1982). Visando à sobrevivência, gestores buscam no ambiente fontes de aprendizado, para tornar as rotinas mais adequadas às conjunturas ambientais. Em face do ambiente, a aprendizagem dá-se, assim, como um processo heurístico, continuado, de erro e correção, buscando a solução dos problemas.

A consideração das alterações ambientais conduziu à ideia de capacidades dinâmicas (TEECE; PISANO; SHUEN, 1997). Quando e como uma vantagem competitiva deixa de ser uma vantagem depende, em parte, da estabilidade da demanda de mercado e de movimentos de concorrentes no sentido de imitar as práticas da empresa - ambos fatores relacionados com o ambiente externo da organização. Assim, as conjunturas ambientais requerem das organizações que se mantenham em um processo dinâmico, de permanente construção de novas capacidades.

\section{Ambiente e escolha estratégica}

A discussão que põe em pauta o dilema entre voluntarismo e determinismo procede da relevância da consideração do ambiente como importante fonte da formulação de estratégias. Seriam os gestores capazes de exercer escolhas estratégicas em face de mudanças, transformações e imprevistos ambientais ou simplesmente reagiriam às pressões, a elas adaptando a organização, sem terem à disposição um 
leque amplo de possíveis ações apropriadas a serem escolhidas? Em outras palavras, as organizações conduzem-se voluntariamente ou são conduzidas deterministicamente?

Em modelos abarcados sob a denominada visão sistêmico-estrutural, prevalece a compreensão de que as organizações se adaptam ao ambiente, sendo a ele reativas, enquanto em modelos abarcados sob a denominada visão de escolha estratégica, impera o entendimento de que o comportamento organizacional é construído, autônomo e representado, sendo os gestores proativos (ASTLEY; VAN DE VEN, 1983). Excluindo-se a seleção alternativa de uma ou outra característica, não seria incoerente ponderar que a trajetória organizacional é marcada por algum grau de determinismo, assim como por algum grau de voluntarismo, ou seja, que empresa e ambiente exercem um sobre o outro - o que, por vezes, se realça em nível regional - influência mútua (PORTER, 1991). A dicotomia pura e irrefletida entre voluntarismo e determinismo tende a gerar simplificações pouco úteis à compreensão das escolhas estratégicas (WHITTINGTON, 1988).

Notadamente, duas teorias aportam questões interessantes sobre o tema: a teoria contingencial e a teoria evolucionária. A teoria contingencial originouse de pesquisas sobre a estrutura organizacional (BURNS; STALKER, 1961; WOODWARD, 1965; LAWRENCE; LORSCH, 1967). Suas origens dirigiram-se mais à análise da estrutura organizacional que da indústria. A teoria preconiza que a estrutura organizacional adequada é constituída a partir da consideração de dois elementos: as contingências ambientais que circundam a organização e o tipo de tecnologia sobre o qual ela se sustenta.

Relacionada ao tema, a questão que se coloca é se as contingências ambientais determinam o sucesso das estratégias empregadas ou se aos gestores é delegada alguma discricionariedade na escolha de um conjunto de estratégias possíveis que conduziriam a organização a bons desempenhos. As circunstâncias, por si só, provavelmente não determinam o desempenho da organização, porém é certo que estabelecem limites às possibilidades de escolha que se colocam aos gestores. Não há apenas a estratégia planejada, como a estratégia não é sempre imposta (MINTZBERG; WATERS, 1985), ou seja, o ambiente não é apenas plenamente controlável, mas também não é apenas plenamente impositivo.
A teoria evolucionária, por seu turno, inspirada em modelos evolucionistas naturais, oferece sobre a influência do ambiente no desempenho da organização uma visão destacadamente determinista. Semelhantemente à seleção natural, o ambiente selecionaria também as organizações mais adaptadas (HANNAN; FREEMAN, 1977), em detrimento das menos adaptadas. A escolha gerencial não seria, no entanto, na teoria evolucionária, desprovida de sentido: a adaptação bem sucedida de rotinas que levam a melhores desempenhos poderia ser praticada por meio da aprendizagem organizacional (NELSON; WINTER, 1982).

O peso que se dá ao ambiente tem sido, enfim, questão fundamental em diversas abordagens do campo. É inquestionável que fatores externos influenciam as estratégias e o desempenho das organizações; o que instiga reflexões é a medida em que isso acontece, ou seja, que peso se pode atribuir ao ambiente. Vale pontuar que, muito embora a sobrevivência e o desempenho dependam de pressões ambientais e de capacidade adaptativa, organizações e estratégias são criadas inicialmente por gestores, que exerceram suas escolhas.

\section{As empresas de médio porte no contexto brasileiro}

O mercado de médias empresas é usualmente designado por middle market, expressão que se tornou notória também no Brasil. "As melhores do middle markel", lista divulgada periodicamente pela IstoÉ Dinheiro (ISTOÉ, 2017), chama atenção para um diversificado e volumoso grupo de empresas atuante nesse segmento. Não é necessária mais que uma breve visualização da lista para reconhecer a importância socioeconômica das médias empresas para o país.

Uma extensa parte - possivelmente a maior parte das considerações relativas ao porte empresarial trata de modo conjunto pequenas e médias empresas, sob a sigla PMEs (pequenas e médias empresas). Os exemplos sobejam: Estadão PME (ESTADAO, 2017), G1 PME (G1, 2017), o anuário "As PMEs que mais crescem no Brasil”" (DELOITTE, 2014), entre tantos outros. $\mathrm{Na}$ academia, historicamente, não tem sido diferente (e.g., HEXSEL; LAGRECA, 2007; TAVARES; PACHECO; ALMEIDA, 2015). Expressão semelhante que também aparece na literatura é "micro, pequenas e médias empresas" (MPMEs) (e.g., SOUZA; CORREA, 2014). Paralelamente, também não é incomum a tratativa conjunta de médias e grandes empresas (MGEs), o 
que faz sentido especialmente quando essa categoria é comparada com a categoria usualmente designada por micro e pequenas empresas (MPEs) (e.g., SEBRAE, 2015). Diferentemente, no entanto, do que ocorre com pequenas e grandes empresas, que, a despeito de serem associadas a empresas de outros portes, também recebem tratamento distintivo (são fartas as referências específicas a pequenas e a grandes empresas), a média empresa como categoria particular tem sido preterida. Isso dificulta que se estabeleçam em torno do médio porte delineamentos teóricos consistentes. Seu próprio conceito não deixa de apresentar, ainda, alguma opacidade.

Não obstante, ainda que por vias alternativas (como se procede nesta seção), é possível resgatar elementos contextuais que contribuem para a compreensão da empresa de médio porte no cenário nacional. Utilizamse, aqui, documentos publicados pelo Serviço Brasileiro de Apoio às Micro e Pequenas Empresas (Sebrae) (SEBRAE, 2014, 2015) cujo enfoque são as micro e pequenas empresas, mas que apresentam, para fins de comparação, dados sobre médias empresas também. Resgatam-se do Anuário do Trabalho na Micro e Pequena Empresa alguns dados básicos, para aclarar a ideia do que representa a figura da média empresa no país. O documento resulta da parceria entre o Sebrae e o Departamento Intersindical de Estatística e Estudos Socioeconômicos (DIEESE) e compila dados da Pesquisa Nacional por Amostra de Domićlios (Pnad), da Pesquisa de Emprego e Desemprego (PED) e do próprio Sebrae. A versão utilizada, publicada em 2015, é a última disponível na seção "estudos e pesquisas" do site.

Além do faturamento, critério utilizado pelo BNDES para caracterização do porte empresarial, outro critério empregado é o número de pessoas ocupadas. Coerentemente, o Sebrae (2014) distingue entre i) serviços e comércio e ii) indústria. Considera-se média empresa o serviço ou comércio que ocupa de 50 a 99 pessoas e a indústria que ocupa de 100 a 499 pessoas. A despeito da ênfase atribuída às MPEs, que constituem a maior parte dos estabelecimentos do país (em diversos anos representando mais de 99\% dos estabelecimentos brasileiros), são as médias empresas que, em número, apresentam tendência de crescimento. No período de 11 anos coberto pelo Anuário (de 2003 a 2013) (SEBRAE, 2015), as médias empresas passaram de 0,5 para 0,6 e depois para $0,7 \%$ dos estabelecimentos, considerados os setores de indústria construção, comércio e serviços, percentual que representava, no ano final, 45.115 estabelecimentos. As grandes empresas eram, no mesmo ano, 25.127 estabelecimentos.

Segundo o Anuário (SEBRAE, 2015), o número de empregos em médias empresas, subiu de $2.849 .276 \mathrm{em}$ 2003 para 5.027.167 em 2013. Embora o percentual em relação à população tenha diminuído nesse período, ainda assim é de se reconhecer o volume significativo de empregos em médias empresas. O principal setor é a indústria, que, no último ano, concentrava 2.192.599 empregos, 43,61\% do total em médias empresas. Em relação ao total de empregos em cada setor, é na construção (setor em que atuam as empresas pesquisadas nos estudos de caso) que as médias empresas se destacam. Elas respondiam em 2013 por $27,1 \%$ dos empregos do setor. No mesmo ano, foram gerados (em comparação com o ano anterior) 116.482 empregos formais nas médias empresas.

Vale atentar, ainda, segundo o Anuário (SEBRAE, 2015), para o fato de que a remuneração média real dos empregados em médias empresas era, no último ano apurado, significativamente superior à remuneração média em MPEs. Enquanto naquelas o valor era de $\mathrm{R} \$ 2.189,00$, nestas era de $\mathrm{R} \$ 1.485,00$, ou seja, a remuneração em médias empresas era $47,4 \%$ maior. Nesse ano, $17,9 \%$ da massa de remuneração real estava concentrada em médias empresas, percentual que corresponde a mais de $\mathrm{R} \$ 10,5$ bilhões. Quando se considera especificamente o setor de construção civil, a concentração da massa de remuneração real sobe de $17,9 \%$, para $28,9 \%$, o que demonstra a importância das médias empresas para esse setor. Enfim, no contexto brasileiro, a despeito do déficit de atenção dispendido ao médio porte como categoria particular, não faltam evidências que atestam ser essa uma categoria bastante expressiva. Nomeadamente no setor de construção civil, essa expressividade, em alguns aspectos, inclusive ganha em destaque.

\section{Procedimentos metodológicos}

A definição dos procedimentos foi norteada pelos objetivos a que se propôs a pesquisa, optando-se porum estudo de casos multíplice, conduzido sob perspectiva longitudinal. Pelo multicaso, visou-se possibilitar o cotejamento de resultados, de forma a majorar a validade externa do estudo (POZZEBON; FREITAS, 1998). Os casos interessaram instrumentalmente (CRESWELL, 2013), como espaços de ocorrências 
fáticas não simuladas, dados à aproximação empírica dos movimentos de pesquisa, os quais se abalizaram pelos procedimentos sugeridos por Eisenhardt (1989).

Os casos foram selecionados tendo-se em vista a contribuição teórica que as análises resultantes poderiam oferecer à teoria e à prática gerencial. A escolha dotou-se, portanto, de qualidade teórica, não randômica, ou amostral: casos "teoricamente úteis", como define Eisenhardt (1989, p. 533), e "intencionais, mais que aleatórios", como observam Miles e Huberman (1994, p. 27). Foram três as empresas exploradas, seletadas de acordo com os seguintes critérios: (i) classificadas como médias empresas, conforme parâmetros adotados pelo BNDES (BNDES, 2017); (ii) faturamento mais próximo do limite que distingue médias empresas de pequenas que do limite que distingue médias de grandes; (iii) ter por atividade principal a incorporação imobiliária; (iv) reconhecimento de mercado, observando-se os seguintes parâmetros: reconhecença por especialistas; capacidade de venda de imóveis na planta; reduzido nível de unidades imobiliárias em estoque; capacidade de gerenciamento simultâneo de várias obras; (v) inexistência de controle societário por alguma empresa de grande porte; (vi) estrutura de capital privado e gestão pelos próprios proprietários.

A opção por empresas integrantes de um mesmo setor e de uma mesma região visou a possibilitar comparações, na medida em que, sendo comuns a todos os casos, restam, sob uma perspectiva objetiva, imobilizados os parâmetros ambientais (MOSAKOWSKY, 1993; YANG; LIN; LIN, 2010). Destacam-se, no Quadro 1, propriedades básicas do lócus de pesquisa.

Quadro 1. Propriedades do lócus de pesquisa

\begin{tabular}{|c|c|}
\hline Propriedades & Descrições/fundamentos \\
\hline Setor estruturado & $\begin{array}{l}\text { A relativa estabilidade de estruturas lógicas e conceituais viabiliza definições claras } \\
\text { dos casos e dos contextos }\end{array}$ \\
\hline Diversidade de portes & $\begin{array}{l}\text { A diversidade implica um estado de competição entre empresas de diferentes } \\
\text { portes, o que instiga à compreensão das especificidades inerentes à cada qual }\end{array}$ \\
\hline $\begin{array}{l}\text { Inexistência de competidor } \\
\text { dominante }\end{array}$ & $\begin{array}{l}\text { Pressupõe a existência de competição; consequentemente, de estratégias } \\
\text { competitivas }\end{array}$ \\
\hline Existência de serviço & $\begin{array}{l}\text { Significa que o setor se mantém operante, movido por dinâmicas empresariais } \\
\text { resultantes de ações estratégicas }\end{array}$ \\
\hline $\begin{array}{l}\text { Circunscrição geográfica não } \\
\text { extensa }\end{array}$ & $\begin{array}{l}\text { Não sendo a região uma circunscrição grande, é possível compreender relativamente } \\
\text { bem os elementos do setor }\end{array}$ \\
\hline Semelhança com outras regiões & $\begin{array}{l}\text { A região, em alguma medida, pode refletir a situação de outras cidades de médio } \\
\text { porte do país, entre as quais há várias relevantes }\end{array}$ \\
\hline
\end{tabular}

Fonte: elaborado pelos autores.

Conforme recomendado (EISENHARDT, 1989; CRESWELL, 2013; GERRING, 2007; YIN, 2010), os dados foram coletados por meios e fontes diversas. Os esforços de coleta foram orientados por um roteiro, visando-se a estruturação das práticas de pesquisa (MILES; HUBERMAN, 1994). Propiciando a instituição de parâmetros, o roteiro viabilizou que se procedesse a comparações entre os casos, bem como à triangulação dos dados provenientes de fontes diversas. Detalham-se, no Quadro 2, os dados colhidos. 
Quadro 2 . Tipos e volumes de dados colhidos

\begin{tabular}{|c|c|c|c|}
\hline Materiais coletados & Caso A & Caso B & Caso C \\
\hline Entrevistas & $\begin{array}{l}9 \\
\text { dirigente-proprietário, } \\
\text { membro familiar, gestor } \\
\text { não familiar, fornecedor, } \\
\text { parceiro comercial, consultor, } \\
\text { investidor }\end{array}$ & $\begin{array}{l}8 \\
\text { dirigente-proprietário, } \\
\text { membro familiar, gestor } \\
\text { não familiar, fornecedor, } \\
\text { consultor, investidor }\end{array}$ & $\begin{array}{l}5 \\
\text { dirigente-proprietário, } \\
\text { membro familiar, } \\
\text { fornecedor, consultor, } \\
\text { investidor }\end{array}$ \\
\hline Notícias da imprensa & $\begin{array}{l}81 \\
\text { Jornal de Londrina, Folha de } \\
\text { Londrina, Jornal Nossa Terra } \\
\text { e outros }\end{array}$ & $\begin{array}{l}136 \\
\text { Jornal de Londrina, Folha de } \\
\text { Londrina e outros }\end{array}$ & $\begin{array}{l}47 \\
\text { Jornal de Londrina, Folha } \\
\text { de Londrina e outros }\end{array}$ \\
\hline Documentos & $\begin{array}{l}3 \text { tipos - dossiê de } \\
\text { empreendimentos, materiais } \\
\text { publicitários e modelos } \\
\text { contratuais }\end{array}$ & $\begin{array}{l}2 \text { tipos - dossiê de } \\
\text { empreendimentos e } \\
\text { materiais publicitários }\end{array}$ & $\begin{array}{l}2 \text { tipos - dossiê de } \\
\text { empreendimentos e } \\
\text { materiais publicitários }\end{array}$ \\
\hline Fotos & $\begin{array}{l}21 \text { projetos } \\
\text { Obras executadas em etapas } \\
\text { variadas da vida da empresa }\end{array}$ & $\begin{array}{l}20 \text { projetos } \\
\text { Obras executadas em etapas } \\
\text { variadas da vida da empresa }\end{array}$ & $\begin{array}{l}20 \text { projetos } \\
\text { Obras executadas em etapas } \\
\text { variadas da vida da empresa }\end{array}$ \\
\hline Hotsites & 2 & 5 & 2 \\
\hline Vídeos & 12 & 11 & - \\
\hline $\begin{array}{l}\text { *Entrevistas com } 4 \\
\text { (SINCIL), um consu }\end{array}$ & $\begin{array}{l}\text { tas: o Presidente do Sindic } \\
\text { mado na região, o Secretát }\end{array}$ & $\begin{array}{l}\text { dos Corretores de Imóveis d } \\
\text { e Obras do Município de Lo }\end{array}$ & $\begin{array}{l}\text { Londrina e Região } \\
\text { adrina, um Professor da }\end{array}$ \\
\hline
\end{tabular}

Fonte: elaborado pelos autores.

Os dados foram analisados buscando-se, através de interpretação, ligarem-se dados a conclusões (GERRING, 2007). Procedeu-se, primeiramente, às análises intracaso (within-case analysis), e, na sequência, à análise intercaso (cross-case analysis), pela qual se colacionaram as constatações observadas (EISENHARDT, 1989).

As análises de cada caso foram precedidas da definição de termos analíticos. Identificaram-se: atores estratégicos; momentos estratégicos; circunstâncias ambientais e internas; e ações estratégicas realizadas. Reconhecendo-se a relevância de ocorrências históricas na compreensão da ação estratégica (MINTZBERG, 2007), cada caso foi, então, analisado cronologicamente, enfatizando-se as ocorrências constatadas nos momentos diversos. Considerou-se todo o período transcorrido entre a fundação da empresa e o ano de 2013. Os reconhecimentos resultantes das análises intracaso embasaram a análise intercaso. Táticas sugeridas por Eisenhardt (1989) foram, então, utilizadas - em especial, o desenvolvimento de categorias e dimensões que facultassem a observação de similaridades e dissimilaridades e a consideração dos dados em função de suas fontes originárias.

\section{Análise e discussão dos dados e resultados}

Os casos estudados deixam clara a existência de uma circunscrição interna muito significativa, especialmente em razão da presença atuante do fundador e de membros familiares. Não se trata, no entanto, de uma ambiência 
fechada. É comum que atores externos transpassem, em certos momentos, as fronteiras organizacionais, para atuar como se fossem membros da empresa. É o que se constata, por exemplo, quando consultores externos ficam responsáveis pela elaboração de planilhas orçamentárias de novos projetos. Muitos dos atores, relacionando-se com as empresas há décadas, alguns inclusive com exclusividade, acabaram por mesclar-se com a estrutura interna. Definir as fronteiras organizacionais não é tarefa simples e as escolhas a elas referentes podem ser movidas por considerações variadas (HOLMSTROM; ROBERTS, 1998). Nos casos estudados, nota-se que, assim como as empresas incorporam contratos antes mantidos entre as relações de mercado, elas também transferem para o domínio do mercado relações antes mantidas sob o controle hierárquico, movimentos esses que são determinados, em extensa medida, pela atuação do dirigente-proprietário, por vezes de modo até relacionado com ocorrências de âmbito privado. As empresas pesquisadas submetem-se a pressões de ordens variadas que são próprias do porte-legislativas, por exemplo - e que tornam recorrentes as decisões referentes às fronteiras organizacionais.

Reflexões como as contidas no artigo clássico de Coase (1937) e nas contribuições exercidas posteriormente por Williamson (1985) demonstram ser a delimitação da firma uma empreita muito mais complexa do que usualmente se tende a pensar. Embora seja inegável a distinção entre a organização e o conjunto de transações que compõem o mercado, em muitas situações, tendo-se em vista as mesclas estruturais ocorridas entre a organização e atores externos, parece ser mais propício conceber as fronteiras organizacionais a partir da consideração de domínios compartilhados. Entre os atores mais próximos, destacam-se escritórios de arquitetura, consultores, fornecedores de projetos e escritórios de assessoria contábil. São esses atores que constituem o ambiente operacional da firma (LÄNSILUOTO, 2004), ligados corriqueiramente às suas operações. As dimensões ambientais não são, no entanto, independentes umas das outras. Os casos estudados apontam que a composição do ambiente operacional - diretamente influenciada pela atuação do dirigente-proprietário intervém sobre a composição das demais dimensões. Aspectos tecnológicos ou sociais, por exemplo, integrados no macroambiente (LÄNSILUOTO, 2004), confrontam a empresa de modos variados, a depender da rede que se configura no seu ambiente operacional. Isso indica o elevado peso do dirigente-proprietário no comportamento estratégico da empresa.
A proximidade da organização com atores externos, que, portanto, influencia a formatação de dimensões e atributos ambientais, é função, em extensa medida, do relacionamento mantido entre o dirigente-proprietário - e (nos casos estudados), em tempos recentes, também os membros familiares - e o representante do ator. Os resultados apontam, assim, para uma proposição segundo a qual as ações estratégicas são, em médias empresas, influenciadas pelo grau de proximidade do relacionamento mantido entre o dirigente-proprietário, ou membros familiares sucessores, e os representantes de atores externos, a partir do que se formatam as dimensões e os atributos ambientais (Proposição 1).

Decisões estratégicas são influenciadas pelo modo como os gestores concebem o ambiente (MINTZBERG; AHLSTRAND; LAMPEL, 2000), em um contexto decisório de racionalidade limitada (SIMON, 1976). Nas empresas estudadas, mesmo tendo-se constituído em todas elas equipes de direção familiares, a percepção do fundador parece ainda ser a mais influente. Como forma de controle, notou-se o desenvolvimento de relações críticas entre o fundador e outros atores, como membros familiares e consultores, em busca de algum "mapa" (WEICK, 1995), para administrar o risco de se desconsiderarem elementos concretos do ambiente. Essas relações desenvolvemse com certa naturalidade. É na comunicação com os pares que os dirigentes muitas vezes buscam controlar a assertividade de suas interpretações, o que parece guardar alguma relação com o disposto em Hines (1988).

Fica evidente, nos casos, que há partes mais próximas e partes menos próximas da empresa, compondose ambientes em diferentes níveis de imediações (HATCH, 1997). O que muitas vezes distingue as relações é o contato direto com os dirigentes, de tal modo que a variação de níveis não se dá tanto em função da categoria objetiva da parte quanto da qualidade da relação. Nota-se que a proximidade de alguns atores é consequência do momento no qual a relação se iniciou. As parcerias de fornecimento mais intensas, por exemplo, tendem a se dar com fornecedores com os quais a aproximação ocorreu antes da departamentalização das empresas (consequência do crescimento), quando era possível que o contato se desse diretamente com o fundador.

Em geral, as empresas mantêm pouco contato com representantes de atores mais distantes, como agências reguladoras ou instituições normativas. Tal fato deve ser consequência de restrições relativa ao porte das 
empresas. Constatam-se, no entanto, algumas exceções. Uma das empresas estudadas, por exemplo, atuando também em cidades menores, consegue aproximar-se em grau relativamente intenso de gestores públicos executivos e das casas legislativas dos municípios. Dessa aproximação, podem decorrer impactos proeminentes no cenário local, como modificações de normas urbanísticas. Ou seja, mesmo em relação a componentes do ambiente geral, como normas legais (HATCH, 1997), e ainda que em caráter excepcional, as empresas não se encontram sempre sob submissão completa às condições ambientais. À visão da seleção natural (HANNAN; FREEMAN, 1977) contrapõemse, mesmo quando se trata de empresas distantes do grande porte, vias de mutualidade, reforçando-se visões como a da escolha estratégica (ver Astley e Van de Ven, 1983).

Interessante destacar que os estados ambientais características que qualificam o ambiente em dado momento - variam em função de atributos objetivos e também de atributos que são próprios da relação que a empresa mantém com seu meio. Os altos índices inflacionários, por exemplo, marcaram os contextos das empresas na década de 1980 e no início da década de 1990, criando entrechos instáveis aos quais as empresas responderam optando pelo sistema de condomínio de incorporação. De acordo com a classificação utilizada por Dess e Beard (1984), um ambiente dinâmico, de mudanças pouco previsíveis. Essa imprevisibilidade resultou da agudeza das mudanças econômicas acontecidas no período (WITTMANN; LÜBECK; NELSIS, 2013). Essa foi uma circunstância gerada por atributos objetivos, cuja resultante impactou de modo comum as empresas integrantes do setor.

Diferentemente, há momentos em que se percebe que o estado ambiental modela-se em função de questões particulares da empresa. Porter (1991) coloca que diferenças entre empresas baseadas em uma mesma região parecem ser, em parte, função do subambiente de cada empresa. Em um dos casos estudados, por exemplo, enquanto o ambiente, em meados da década de 2000, era favorável à expansão das atividades, a empresa, durante aproximadamente dois anos, não lançou novas incorporações no mercado, devido a problemas privativos, que refletiram, especificamente para ela, hostilidade ambiental. A empresa passou, então, por um período de reafirmação de credibilidade em relação a consumidores e fornecedores.

Regionalmente, na esfera ambiental geograficamente imediata, os resultados apontam, de forma alinhada com a literatura revisada (PORTER, 1991) que a influência mútua exercida das empresas sobre o ambiente e deste sobre as empresas é significativa. Em razão da circunscrição de atuação, restrita ao mercado regional, as influências são marcadamente perceptíveis. Ao optar pela abertura de uma nova região na década de 1980, uma das empresas estudadas iniciou um movimento urbano que viria a resultar, duas décadas depois, no bairro com maior volume de lançamentos da cidade. Para Porter (1991, p. 115), “o ambiente local cria potencial para sucesso competitivo, mas as empresas precisam perceber e responder a isso".

Da mesma forma, as dinâmicas setoriais que se seguiram ao movimento pioneiro da empresa, se não determinaram, pelo menosinduziram ações estratégicas que deram à empresa o estilo pelo qual ela se firmou: uma incorporadora de empreendimentos de padrão elevado, construídos pelo sistema de condomínio. Por outro lado, assim como acontecimentos locais relevantes são influenciados pelo comportamento das empresas e orientam seus futuros, não é sempre fácil perceber a relação havida entre seus comportamentos e acontecimentos ocorridos em níveis ambientais mediatos, o que se explica pelo porte não expressivo das empresas. Utilizando-se a classificação de Scott (2003), talvez se possa afirmar que tende a ser mais manifesta a influência da empresa sobre a dimensão técnica do que sobre a dimensão institucional.

Confirma-se, assim, a intensidade da ligação mantida entre a empresa e o setor regional, o que aponta para uma segunda proposição, segundo a qual as ações estratégicas de médias empresas resultam da necessidade da organização de gerenciar sua posição nos ambientes operacionais imediatos nos quais opera, como os formados a partir da relação entre a empresa e fornecedores, investidores e parceiros comerciais, em razão de que, significativamente, a organização é impactada pelo setor regional, ao mesmo tempo que o impacta (Proposição 2).

O meio confere aos dirigentes a prerrogativa de realizar análises apositivas, acrescendo às compreensões dos fatores internos da empresa compreensões acerca do ambiente. Parece ser disso que resultam as escolhas estratégicas (CHRISTENSEN et al., 1982). Os dirigentes esforçam-se para conseguir a extração de algum sentido dos fatos correntes da vida organizacional (SMIRCH; STUBBART, 1985), já que o sucesso das estratégias pode depender não apenas da assertividade das intepretações das condições ambientais como também do estabelecimento hermenêutico de um sistema organizacional. 
Os resultados indicam que o relacionamento com fornecedores, parceiros comerciais e consultores é utilizado como meio de controle de assertividade. Nota-se que o compartilhamento de noções sobre o ambiente influencia a realidade objetiva, criando-a a partir de ideias. Os dirigentes-proprietários de médias empresas, centralizando o controle de estratégias, desempenham o papel fundamental de compartilhar entendimentos, para criar projetos de negócio a partir daquilo que ficou conhecido na teoria dos recursos (DIERIKX; COOL, 1989) como estoques de ativos disponíveis. O ajuste entre o ambiente e as capacitações da empresa (RAYMUNDO; CONTADOR; CONTADOR, 2013) é atividade das mais relevantes.

Em um dos casos estudados, o projeto lançado no centro velho da cidade em 2007 é um exemplo. Havia mais de décadas que não se incorporavam empreendimentos na região. $O$ fundador juntou investidores, fornecedores e um parceiro comercial, vendendo uma ideia diferente do entendimento geral então vigente. Esse movimento contou com a participação de membros familiares, que atuaram como elo para agregar os investidores. À época um dos maiores projetos verticais já aprovados pela prefeitura local, a incorporação foi extremamente bem sucedida, evidenciando um movimento estratégico desenvolvido por meio do rompimento de paradigmas, fomentado pela empresa para otimizar recursos e capacidades que estavam ociosos. Esse exemplo demonstra que o ambiente é percebido em função dos repertórios individuais que embasam a percepção (DOWNEY; SLOCUM, 1975). Nas empresas estudadas, essa percepção é sugestionada fortemente pelo dirigenteproprietário e pelos membros familiares que intervêm sobre as decisões. Dess e Origer (1987) relembram que a avaliação do ambiente é considerada uma atividade antecedente à formulação de objetivos e de métodos competitivos. Uma terceira proposição emerge, assim, daí: As ações estratégicas resultam, em médias empresas, da interpretação do dirigente-proprietário acerca das circunscrições interna e externa, e do compartilhamento de conceitos de negócio, que, em empresas familiares, sofre influência do âmbito familiar, situado dentro e fora das fronteiras organizacionais (Proposição 3).

A interação entre a empresa e o contexto regional imediato também é percebida no posicionamento que a empresa assume em virtude das ocorrências ambientais com as quais se depara (PORTER, 1991), e consequentemente também na sua estrutura. Os resultados evidenciam que as ações estratégicas são concebidas e implementadas em função de forças ambientais diversas, oriundas de fontes igualmente diversas. O incremento da demanda ocorrido em meados da década 2000 coincidiu - e foi em extensa medida também por elas gerado - com a ocorrência de alterações no sistema financeiro, em decorrência do que duas das empresas estudadas, que operavam com incorporações a preço fechado, responderam não apenas com a adequação do portfólio ao perfil das classes então emergentes, como também tiveram de readequar seus métodos de gestão de fluxo de caixa. Trata-se de mudanças substanciais, que demonstram a propensão das empresas de mudar e a disposição à revisão de posturas. Essa atitude é estimulada especialmente pelo dirigente-proprietário ou por sucessores, que, assumindo a mutação ambiental como uma constante, suscitam nos indivíduos a capacidade de aprender (ARGYRIS; SHÖN, 1978).

A habilidade de se adaptar a novas circunstâncias é, pois, uma das habilidades organizacionais fundamentais. Vantagens competitivas resultam de ocorrências processuais (TEECE; PISANO; SHUEN, 1997). Especialmente em uma das empresas estudadas - a mais antiga delas -, nota-se que as ações estratégicas variaram muito ao longo do tempo. A sobrevivência das empresas, principalmente em momentos adversos (ou hostis conforme classificação de Mintzberg, 1979) - como os períodos de inflação alta das décadas de 1980 e 90, e quando grandes incorporadoras de fora ingressaram na praça introduzindo novos padrões de atuação, na década de 2000 -, deveu-se a suas capacidades adaptativas, expressadas por meio do reforço de ações estratégicas já realizadas, ou da sua remodelagem. As mudanças estratégicas aí operadas não se deram - alinhado com o que observam Teece, Pisano e Shuen (1997) - facilmente, mas ocorreram, como se pode observar por um estudo conduzido sob perspectiva longitudinal, incrementalmente.

Os resultados dão a entender que a centralização da coordenação de rotinas na figura do dirigenteproprietário, oapoiodemembrosfamiliaresea existência de uma rede forte de parcerias interempresariais contribuem para que as empresas formulem respostas tempestivas. As empresas estudadas, por meio da atuação marcante principalmente do dirigenteproprietário, conseguem converter o conhecimento das necessidades de adaptação em rotinas que tornam efetivos os movimentos adaptativos. A partir da aprendizagem, reformulam-se rotinas (NELSON; WINTER, 1982). 
Os resultados apontam, assim, para uma quarta proposição, segundo a qual as adaptações de rotinas necessárias em função das alterações ambientais são protagonizadas pelo dirigente-proprietário, e concorrem para a tempestividade dessas adaptações o apoio interno da equipe de dirigentes e a sinergia mantida pela empresa nas redes constituídas por ela e por atores externos (Proposição 4).

Representa-se, na Figura 1, uma sinopse do diagnóstico realizado da relação entre empresa e ambiente.

Figura 1. Relação entre a empresa e o ambiente

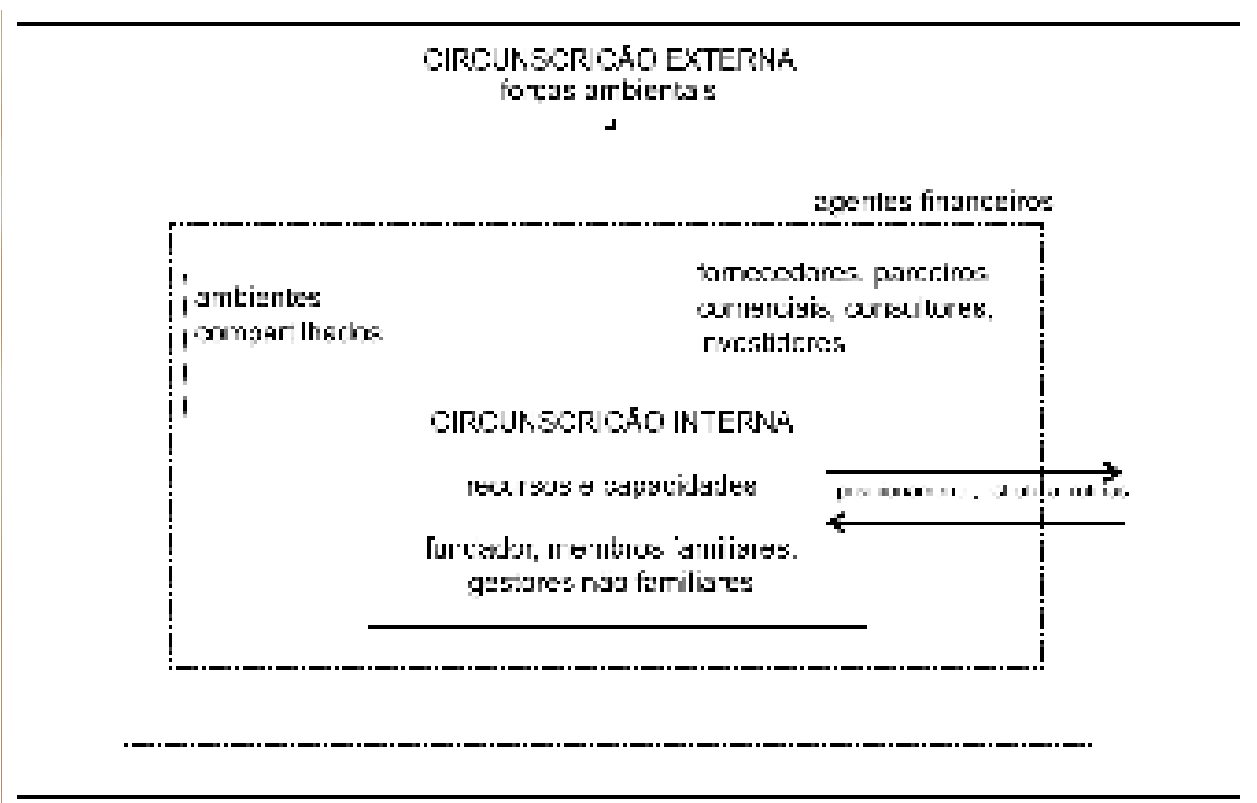

Fonte: elaborada pelos autores.

No Quadro 3, compilam-se as proposições emergentes do estudo.

Quadro 3 . Proposições decorrentes dos casos

\begin{tabular}{cll}
\hline Proposições & Enunciados & Aportes teóricos \\
\hline 1 & As ações estratégicas são, em médias empresas, & Dess e Beard (1984), Hatch (1997), \\
& influenciadas pelo grau de proximidade do & Mintzberg (1979), Scott (2003), Länsiluoto \\
& relacionamento mantido entre o dirigente-proprietário, & $(2004)$ \\
& ou membros familiares sucessores, e os representantes & \\
& de atores externos, a partir de que se formatam as & \\
& dimensões e os atributos ambientais.
\end{tabular}

2 As ações estratégicas de médias empresas resultam da

Porter (1991), Länsiluoto (2004) necessidade da organização de gerenciar sua posição nos ambientes operacionais imediatos nos quais opera, como os formados a partir da relação entre a empresa e fornecedores, investidores e parceiros comerciais, em razão de que, significativamente, a organização é impactada pelo setor regional, ao mesmo tempo que o impacta. 
3 As ações estratégicas resultam, em médias empresas, da interpretação do dirigente-proprietário acerca das circunscrições interna e externa, e do compartilhamento de conceitos de negócio, que, em empresas familiares, sofre influência do âmbito familiar, situado dentro e fora das fronteiras organizacionais.
Downey e Slocum, (1975), Simon (1976), Christensen et al. (1982), Smircich e Stubbart (1985), Dess e Origer, 1987, Hines (1988), Barney (1991), Weick (1995), Holmstrom e Roberts (1998), Mintzberg, Ahlstrand e Lampel (2000)
As adaptações de rotinas necessárias em função das alterações ambientais são protagonizadas pelo dirigente-proprietário, e concorrem para a tempestividade dessas adaptações o apoio interno da equipe de dirigentes e a sinergia mantida pela empresa nas redes constituídas por ela e por atores externos.
Argyris e Shön (1978), Nelson e Winter (1982), Miller (1979), Porter (1991), Teece, Pisano e Shuen (1997), Crossan, Lane e White (1999)

Fonte: elaborado pelos autores.

\section{Considerações finais}

Este artigo retrata parte de uma pesquisa que tem por finalidade investigar a ação estratégica ocorrida no âmbito da empresa de médio porte. Nesta oportunidade, relatam-se as análises procedidas especificamente da relação entre o ambiente estratégico e as ações perpetradas pelas empresas que protagonizam os casos estudados. Com o fito de nortear os esforços e a organização da pesquisa, estipularam-se três objetivos intermediários.

Por meio de uma exploração longitudinal, detectaramse, inicialmente, as principais ocorrências ambientais com as quais as empresas se defrontaram ao longo do tempo, enfaticamente conjunturas de nível regional - conforme designação do primeiro objetivo intermediário. Percorreram-se, nesse exercício, fatos históricos relevantes que, por toda a extensão da vida das empresas, circunstanciaram suas atuações. No mesmo empreendimento, identificaram-se, concomitantemente, as ações estratégicas utilizadas em face dessas ocorrências, concatenando-as - conforme designação do segundo objetivo intermediário. Em decorrência desse movimento, as ações estratégicas foram depreendidas contextualmente, como comportamentos movidos em meio, ou manifestamente em resposta, a eventos ambientais. O segundo objetivo foi, assim, desempenhado por um movimento associativo, relacionando-se ações estratégicas a conjunturas ambientais.
Foram, portanto, duas as tarefas metodológicas executadas até então: uma de identificação e outra de associação. Nos casos estudados, pôde-se perceber que as ocorrências ambientais não são plenamente objetivas. Especialmente quando é intensa a presença do dirigente-proprietário na empresa (como nos casos), o ambiente que a impacta constitui-se muito em função da sua atuação. Isso porque, a depender dos modos atuação do dirigente-proprietário, os domínios podem ser compartilhados de formas distintas e com atores distintos. Nesse sentido, para o tipo organizacional visado, o ambiente tende a ser muito mais particular do que para organizações de grande porte. A discricionariedade que marca a atuação do dirigente-proprietário, de algum modo, ensejaria, assim, a existência de possibilidades mais amplas de modelagem do ambiente. Essa maneira peculiar de conceber o comportamento estratégico desse tipo de empresa consiste na principal contribuição teórica decorrente do cumprimento dos dois primeiros objetivos. Fica nítido nos casos estudados que as empresas não apenas respondem ao ambiente, mas respondem a um ambiente, em alguma (importante) medida, por elas constituído. Sugere-se que, para aproximar a teoria da realidade sobre a qual ela versa, pesquisas da área de estratégia realizadas com empresas enquadradas entre o tipo visado nesta pesquisa levem isso em consideração.

Das observações provenientes dos casos, partiuse em busca de padrões que permitissem, em 
dimensão minimamente razoável, a compreensão do comportamento estratégico das empresas avaliadas e, na medida do possível, aportassem lampejos à percepção do liame entre a estratégia da média empresa e o ambiente que a envolve. Entre as ações estratégicas identificadas na pesquisa originária, destaquem-se as seguintes: estabelecimento de parcerias com outras empresas; centralização da coordenação imediata de rotinas diversas na figura do fundador ou de dirigente familiar substituto; formação de equipes de direção constituída por membros familiares; desenvolvimento de nichos de negócio; desenvolvimento de produtos diferenciados; captação de recursos financeiros com investidores. Em parte, essas ações constituem modelos de conduta que podem ser explicados em função da relação havida entre a empresa e o ambiente.

A análise do conjunto de ações possibilitou, então, a extração de uma espécie de substrato de ação estratégica, a partir do qual se ordenaram elementos proposicionais que expressam alguns padrões de comportamento estratégico do tipo de empresa visado. A tarefa representada por esse terceiro objetivo intermediário cumpre a função de ajudar (ao menos parcialmente) a preencher a lacuna existente no tratamento teórico conferido à empresa de médio porte. Como demonstrado em seção própria, o médio porte, diferentemente dos demais, é no país usualmente tratado de modo conjunto ou com o pequeno ou com o grande porte. A falta de distinção conceitual acaba inibindo discussões mais específicas. As proposições indicadas neste artigo, ainda que provenientes da análise de casos, podem subsidiar pesquisas futuras nas quais o efeito do porte (do médio porte, no caso) seja considerado metodologicamente relevante para a condução das investigações.

Algumas considerações merecem destaque.

Primeiramente, vale consignar que, na média empresa dotada do perfil das empresas exploradas, costuma ser - assim como de se esperar em organizações de menor porte - bastante estreita a relação travada entre o dirigente-proprietário e o representante do ator externo. Relacionamentos dessa ordem ocorrem frequentemente de modo informal, mediante contato direto. Isso confere à média empresa um modus operandi, além de ágil, versátil, uma vez que os contratos são modelados de acordo com demandas imediatas, tornando-se bem ajustados.

Explorando-se as ações, foram, por consequência, descortinados também os atores que as protagonizam.
Entre os principais atores externos identificados, destaquem-se, fornecedores, parceiros comerciais, consultores, investidores e agentes financeiros. Há, entre eles, aqueles mais distantes, cuja relação com a empresa transcorre sobre bases eminentemente burocráticas. É o caso dos agentes financeiros, que, talvez diferentemente do modo como se dá com grandes corporações, tendem a operar, na relação com médias empresas, por condutas extremamente vinculadas, sem margens expressivas para discricionariedades contratuais. Distintamente, há também aqueles mais próximos, que, a depender de elementos relacionais históricos e da proximidade mantida com o dirigenteproprietário, chegam a praticamente mesclar-se com a estrutura interna. São essas relações que tornam, em alguns pontos, um tanto nebulosas as fronteiras distintivas das ambiências organizacionais interna e externa. Sugere-se que pesquisas futuras realizadas com empresas de médio porte atentem para tal fato. As qualidades dos relacionamentos travados entre o dirigente-proprietário e os representantes dos atores externos são um importante balizador da dimensão da circunscrição ambiental que envolve a média empresa.

Os atores mais próximos exercem papeis que extrapolam o escopo imediato das relações contratuais. No contato direto com dirigentes-proprietários, eles executam funções de contrapeso, regulando as interpretações que os dirigentes fazem do ambiente externo. Esse exercício é sustentado especialmente na diversidade de dados que os atores coletam, de fontes diversas, em decorrência das relações que mantêm com outras empresas, muitas delas também de porte médio. Em medida significativa, atores externos são, assim, utilizados pelos dirigentes como meios de contrabalanceamento dos riscos que podem resultar de erros interpretativos acerca do ambiente externo, riscos esses majorados pelo fato de existirem em muito menor grau, em organizações de menor porte, mecanismos mais sofisticados de controle da assertividade da percepção dos dirigentes, a exemplo da vinculação de decisões a pareceres de consultorias externas independentes - expediente usual em grandes corporações. Essa constatação contribui para estender a compreensão que se tem dos relacionamentos externos mantidos pela empresa, que, no tipo organizacional visado, preservam uma função protetiva (de caráter isomórfico) conduzida pelo próprio dirigente-proprietário. Isso implica que, conforme mudam as relações (até mesmo do âmbito pessoal), pode mudar também o comportamento estratégico da empresa. Pesquisas futuras poderiam 
tentar entender com maior profundidade o impacto de uma variável sobre a outra ao longo do tempo.

Questão que também merece realce é o tom de variabilidade em função de idiossincrasias organizacionais particulares que tinge a suposta - e muitas vezes, metodologicamente admitida objetividade intocável do ambiente externo. Não que essa constatação seja especificamente válida para o tipo estudado, mas dois elementos podem, quando se trata de organizações de menor porte, torná-la relevante. Em se tratando da média empresa, tanto mais, uma vez que nela se nota, como consequência natural do incremento do volume das operações, uma dedicação mais significativa do dirigente-proprietário a atividades coordenativas, o que realça (porque dele se demanda) seu papel de intérprete do ambiente.

O primeiro elemento é de caráter metodológico. Em organizações menores, a fusão entre os ofícios de propriedade e gestão possibilita que a pesquisa adentre concomitantemente dois universos distintos e, ao mesmo tempo, indelineáveis. Esse acesso viabiliza o reconhecimento de relações entre um e outro. O segundo elemento diz respeito, por sua vez, especificamente à proximidade entre os polos de causa e efeito da relação havida entre condições particulares dos dirigentes-proprietários e a forma como o ambiente a eles se apresenta, do que decorrem as interpretações que lhes são dirigidas. Quer-se dizer: porque a empresa ainda se confunde com a figura do fundador, alterações em suas condições pessoais podem fazer emergir alterações de contexto. Tal fato intensifica-se quando a circunscrição de atuação da empresa é estreita, já que ambiências reduzidas favorecem o controle por parte de terceiros, cujas percepções modelam o ambiente; percebendo o proprietário, eles percebem também a empresa.

O estudo realizado sugere implicações para a pesquisa em estratégia, especialmente a que tem por objeto organizações de menor porte e, particularmente, a média empresa. Além dos apontamentos já pautados, ressalte-se a importância de se proceder a recortes longitudinais quando se pretende extrair da ação estratégica algum substrato que se proponha não fugaz. Ao se inserir no escopo a relação entre estratégia e ambiente, tal método resta ainda mais relevante. Diversamente, recortes seccionais tendem a propiciar resultados instantâneos, que expressam relações imediatas entre as condições ambientais havidas em certo momento e as estratégias adotadas, relegando-se, no entanto, a influência da carga histórica, tanto de ocorrências ambientais pretéritas quanto das estratégias adotadas no passado, sobre as ações detectadas.

Ademais, sugere-se que pesquisas futuras aprofundem as particularidades das fontes de mecanismos isomórficos vigentes entre médias empresas. A interpretação do ambiente externo é balizada, em extenso grau, pela interação direta entre o dirigenteproprietário e atores externos que são comuns a outras empresas atuantes na mesma circunscrição. Esses atores, não raro, transitam por diversas empresas e operam como uma espécie de amálgama padronizadora, do que, em alguma medida, decorrem comportamentos estratégicos semelhantes. Em geral, não concorrem para esses comportamentos, como nas grandes corporações, métodos de controle alternativos, como ações políticas exercidas por acionistas. Tampouco, como comum em organizações muito pequenas, são consequências determinadas quase que exclusivamente em resposta a pressões ambientais. Enfim, elementos deve haver que justifiquem a consideração, nesse quesito, da média empresa como categoria particular.

Entre as limitações do estudo, destaquem-se as restrições metodológicas decursivas das semelhanças dos casos selecionados. Se, por um lado, a homogeneidade da amostra viabiliza a preceituação de padrões com relativa confiabilidade - entre outros motivos, porque restam imobilizados, por exemplo, parâmetros ambientais -, por outro, deixam escapar possíveis conclusões relevantes, que poderiam vir à tona como derivação de elementos não presentes nos casos explorados. As empresas tomadas como objeto são, por exemplo, todas familiares. Essa característica provavelmente influiu nas proposições geradas. Também, pode ser que a validade das proposições seja minorada quando se pretender explicar o comportamento de médias empresas que já nasceram no médio porte - como consequência, por exemplo, da cisão de uma empresa maior -, uma vez que os casos estudados são todos de empresas que chegaram ao médio porte em sequência do desenvolvimento partido do pequeno porte. É possível, todavia, que as proposições alvitradas sirvam de base para, sendo o caso, sua própria reformulação. 


\section{Referências}

AGUIAR, J. E.; MELLO JÚNIOR, E. CASTRO,

V. A. Mudanças em ambiente organizacional e o paradoxo discurso versus prática. Revista Alcance, v. 18, n. 2, p. 32-45, 2010.

ALVAREZ, S. A. Small firms, large concerns. Administrative Science Quarterly, v. 46, n. 2, p. 351-353, 2001.

ARGYRIS, C.; SCHÖN, D. A. Organizational Learning. Reading, Mass.: Addison-Wesley, 1978.

ASTLEY, W. G.; VAN DE VEN, A. H. Central perspectives and debates in organization theory. Administrative Science Quarterly, v. 28, n. 2, p. 245-273, 1983.

BAUM, J. A. C. Ecologia Organizacional. In: CLEGG, S. R.; HARDY, C.; NORD. W. R. (Orgs.). Handbook de Estudos Organizacionais, São Paulo: Atlas, 2006. p. 135-193.

BARNEY, J. Firm Resources and Sustained Competitive Advantage. Journal of Management, v. 17, n. 1, p. 99-120, 1991.

BARNEY, J.; WRIGHT, M.; KETCHEN, D. J., JR. The resource-based view of the firm: Ten years after 1991. Journal of Management, v. 27, n. 6, p. 625-641, 2001.

BLAU, P. M. A formal theory of differentiation in organizations. American Sociological Review, v. 35, n. 2, p. 201-218, 1970.

BNDES. Desembolso do sistema BNDES:

Disponível em: http://bndes.gov.br. Acesso em: 30 de jun. 2013.

Porte de empresa. Classificação de porte dos clientes. Disponível em: http:/ /www.bndes.gov. $\mathrm{br} / \mathrm{wps} / \mathrm{portal} / \mathrm{site} /$ home/financiamento/guia/ porte-de-empresa. Acesso em: 27 de jan. 2017.

BURNS, T.; STALKER, G. M. The Management of Innovation. London: Tavistock Publications, 1961.

CHRISTENSEN, C. R. et al. Business Policy: text and cases. Homewood, IL: Irwin, 1982.

COASE, R. The nature of the firm. Economica, v. 4, n. 16, p. 386-405, 1937.

CRESWELL, J. W. Qualitative Inquiry and Research
Design: choosing among five approaches (3rd ed.).

Thousand Oaks: Sage, 2013.

CROSSAN, M.; LANE, H.; WHITE, R. An Organizational Learning Framework: form intuition to institution. Academy of Management Review, v. 24, n. 3, p. 522-537, 1999.

DAVIS, H.; WALTERS, P. Emergent patterns of strategy, environment and performance in a transition economy. Strategic Management Journal, v. 25, n. 4, p. 347-364, 2004.

DELOITTE. PMEs que mais crescem no Brasil. 2014. Disponível em: https://www2.deloitte.com/ $\mathrm{br} / \mathrm{pt} / \mathrm{pages} /$ strategy/articles/pmes.html. Acesso: 02 de fev. 2017.

DESS, G. G.; BEARD, D. W. Dimensions of Organizational Task Environments. Administrative Science Quarterly, v. 29, p. 52-73, 1984.

DESS, G. C.; ORIGER, N. K. Environment, Structure, and Consensus in Strategy Formulation: a conceptual integration. Academy of Management Review, v. 12 , n. 2, p. 313-330, 1987.

DIERICKX, I.; COOL, K. Asset Stock Accumulation and Sustainability of Competitive Advantage. Management Science, v. 35, n. 12, p. 15041511, 1989.

DOWNEY, H. K.; SLOCUM, J. W. Uncertainty: measures, research and sources of variation. Academy of Management Journal, v. 18, p. 562-577, 1975.

EISENHARDT, K. M. Building theories from case study research. The Academy of Management Review, v. 14, n. 4, p. 522-550, 1989.

ESTADAO. Estadão PME. Disponível em: http:// pme.estadao.com.br/. Acesso em: 02 de fev. 2017.

FARACI, R.; SHEN, W. Does firm ownership matter? Investor, corporate governance and strategic competitiveness in privately-held firms. In: DAGNINO, G. B. (Ed.). Handbook of Research on Competitive Strategy. Cheltenham: Edward Elgar Publishing Limited, 2012. p. 536-560.

FAVORETO, R. L.; AMÂNCIO-VIEIRA, S. F. A produção internacional em RBV: características gerais e tratativa dos recursos na pesquisa em organizações de menor porte. Revista Ibero-Americana de Estratégia, v. 13, n. 2, p. 25-37, 2014. 
GERRING, J. Case Study Research. New York:

Cambridge University Press, 2007.

GLOBO. G1 PME. Disponível em: http://g1.globo. com/economia/pme/. Acesso em: 02 de fev. 2017.

GONÇALVES, R. B.; VIEIRA, G. B. B.;

PEDROZO, E. A. O impacto da capacidade absortiva e do aprendizado no desempenho internacional das empresas: um estudo de múltiplos casos. Revista Alcance, v. 21, n. 4, p. 674-694, 2014.

HANNAN, M. T.; FREEMAN, J. H. The population ecology of organizations. The American Journal of Sociology, v. 82, n. 5, p. 929-964, 1977.

HANNAN, M. T.; FREEMAN, J. H. Organizational Ecology. Cambridge, MA: Harvard University Press, 1989.

HANSMANN, H. (Ed.). The ownership of enterprise. Cambridge: The Belknap Press of Harvard University Press, 1996.

HATCH, M. J. Organization theory: modern, symbolic and postmodern perspectives. New York: Oxford University Press, 1997.

HEXSEL, A. E.; LAGRECA, R. A construção e sustentação da vantagem competitiva por pequenas e médias empresas: o caso da Baldo. Revista Eletrônica de Administração, v. 13, n. 3, p. 1-27, 2007.

HINES, R. Financial Accounting: in communicating reality we construct reality. Accounting, Organizations and Society, v. 13, n. 3, 251-261, 1988.

HIT'T, M. A. et al. Strategic Entrepreneurship: integrating entrepreneurial and strategic management perspectives. In: HITT, M. A. et al. (Eds.). Strategic Entrepreneurship: creating a new mindset. Oxford: Blackwell Publishers, 2002. p. 1-16.

HOLMSTROM, B.; ROBERTS, J. The Boundaries of the Firm Revisited. Journal of Economic Perspectives, v. 12, n. 4, p. 73-94, 1998.

ISTOÉ. As melhores do middle market. Disponível em: http://www.istoedinheiro.com.br/noticias/asmelhores-do-middle-market/20151030/500-maioresmiddle-market-100/313459. Acesso em: 27 de jan. 2017.

KAZANJIAN, R. K.; DRAZIN, R. A stagecontingent model of design and growth for technology-based new ventures. Journal of Business
Venturing, v. 5, n. 3, p. 137-150, 1990.

KOTHA, S.; NAIR, A. Strategy and environment as determinants of performance: evidence form the Japanese machine tool industry. Strategic Management Journal, v. 16, n. 7, p. 497-518, 1995.

\section{LÄNSILUOTO, A. Economic and Competitive}

Environment Analysis in the Formulation of Strategy:

A Decision-oriented Study Utilizing Self-organizing Maps. (Relatório de Pesquisa/2004), Turku (FI), Publications of the Turku School of Economics and Business Administration, 2004.

LAWRENCE, P. R.; LORSCH, J. W. Organization and Environment. Boston: Harvard University Press, 1967.

MILES, M. B.; HUBERMAN, A. M. Focusing and bounding the collection of data: the substantive start. In: MILES, M. B.; HUBERMAN, A. M. Qualitative data analysis: an expanded sourcebook (2 ed.). Thousand Oaks: Sage, 1994. p. 16-39.

MILLER, D. Strategy, structure and environment: context influences upon some bivariate associations. Journal of Management Studies, v. 16, n. 3, p. 294-316, 1979.

MILLER, D.; SHAMSIE, J. The resource-based view of the firm in two environments: The Hollywood firm studios from 1936 to 1965. Academy of Management Journal, v. 39, n. 3, p. 519-543, 1996.

MINTZBERG, H. The Structuring of Organizations: a synthesis of the research. Englewood Cliffs, NJ: Prentice Hall, 1979.

MINTZBERG, H. Tracking Strategies: toward a general theory of strategy formation. New York: Oxford University Press, 2007.

MINTZBERG, H.; AHLSTRAND, B.; LAMPEL, J. Safári de Estratégia: um roteiro pela selva do planejamento estratégico. Porto Alegre: Bookman, 2000.

MINTZBERG, H.; WATERS, J. A. Of Strategies, Deliberate and Emergent. Strategic Management Journal, v. 6, n. 3, p. 257-272, 1985.

MOUNT, J.; ZINGER, J.; FORSYTH, G. R. Organizing for development in the small business. Long Range Planning, v. 26, n. 5, p. 111-120, 1993.

MOSAKOWSKI, E. A Resource-Based Perspective on the Dynamic Strategy-Performance Relationship: an Empirical Examination of the Focus and 
Differentiation Strategies in Entrepreneurial Firms. Journal of Management, v. 19, n. 4, p. 819-839, 1993.

NELSON, R. R.; WINTER, S. G. An Evolutionary Theory of Economic Change. Cambridge, Mass.: Harvard University Press, 1982.

PITKETHLY, R. Analyzing the Environment. In: FAULKNER, D. O.; CAMPBELL, A. (Eds.). Oxford Handbook of Strategy: a Strategy Overview and Competitive Strategy. Oxford: Oxford University Press, 2003. p. 162-187.

PORTER, M. E. Competitive Strategy: techniques for analyzing industries and competitors. New York: The Free Press, 1980.

PORTER, M. E. Towards a Dynamic Theory of Strategy. Strategic Management Journal, v. 12, p. 95-117, 1991.

POZZEBON, M.; FREITAS, H. M. R. Pela aplicabilidade com um maior rigor científico dos estudos de caso em sistema de informação. Revista de Administração Contemporânea, v. 2, n. 2, p. 147-170, 1998.

PRAHALAD, C. K.; HAMEL, G. The Core Competence of the Corporation. Harvard Business Review, v. 90, n. 3, p. 79-91, 1990.

QUINN, R. E.; CAMERON, K. Organizational life cycles and shifting criteria of effectiveness. Management Science, v. 29, n. 1, p. 33-51, 1983.

RAYMUNDO, R. V.; CONTADOR, J. L.; CONTADOR, J. C. Abordagens da Estratégia Competitiva e Formulação de Estratégias Empresariais. Revista Pensamento Contemporâneo em Administração, v. 7, n. 4, p. 136-161, 2013.

SCOT'T, W. R. Organizations: rational, natural and open systems (5 ed.). New Jersey: Prentice-Hall, 2003.

SEBRAE. Anuário do trabalho na micro e pequena empresa: 2015. Disponível em: https://www.sebrae. com.br/sites/PortalSebrae. Acesso em: 02 de fev. 2017.

. Participação das Micro Pequenas Empresas na Economia Brasileira. 2014. Disponível em: https://www.sebrae.com.br/sites/PortalSebrae. Acesso em: 02 de fev. 2017.

SIMON, H. A. Administrative Behavior. New York: Free Press, 1976.
SIMON, H. Hidden Champions of the 21st Century: Success Strategies of Unknown World Market Leaders. London: Springer, 2009.

SMIRCICH, L.; STUBBART, C. Strategic management in an enacted world. Academy of Management Review, v. 10, n. 4, p. 724-736, 1985.

SOUZA, A. E.; CORREA, H. L. Indicadores de desempenho em pequenas e médias empresas. Revista Pensamento Contemporâneo em Administração, v. 8, n. 3, p. 118-136, 2014.

TAVARES, F. O.; PACHECO, L.; ALMEIDA, E. F. Financiamento das pequenas e médias empresas: análise das empresas do distrito do Porto em Portugal. Revista de Administração, v. 50, n. 2, p. 254267, 2015.

TEECE, D. T.; PISANO, G.; SHUEN, A. Dynamic Capabilities and Strategic Management. Strategic Management Journal, v. 18, n. 7, p. 509-533, 1997.

VENKATRAMAN, N.; PRESCOT'T, J. E.

Environment-strategy coalignment: an empirical test of its performance implications. Strategic Management Journal, v. 11, n. 1, p. 1-23, 1990.

WEICK, K. E. (1995). Sensemaking in Organizations. Thousand Oaks: Sage Publications.

WERNERFELT, B. A resource-based view of the firm. Strategic Management Journal, v. 5, n. 2, p. 171-180, 1984.

WHITTINGTON, R. Environmental Structure and Theories of Strategic Choice. Journal of Management Studies, v. 25, n. 6, p. 521-536, 1988.

WHITTINGTON, R.; PETTIGREW, A.; THOMAZ, H. Conclusion: doing more in strategy research. In: PETTTIGREW, A.; THOMAZ, H.; WHITTINGTON, R. (Eds.). Handbook of Strategy and Management. London: Sage Publications, 2002. p. 475-488.

WILLIAMSON, O. E. The Economic Institutions of Capitalism: firms, markets, relational contracting. New York: The Free Press, 1985.

WITTMANN, M; L.; LÜBECK, R. M.; NELSIS, V. M. Uma Visão não-Linear sobre Estratégia Empresarial pelo Prisma da Complexidade. Revista Pensamento Contemporâneo em Administração, v. 7, n. 4, p. 117-135, 2013. 
WOODWARD, J. Industrial Organization: Theory and

Practice. London: Oxford University Press, 1965.

YANG, H.; LIN, Z. J.; LIN, Y. L. A multilevel

framework of firm boundaries: firm characteristics, dyadic differences, and network attributes. Strategic

Management Journal, v. 31, n. 3, p. 237-261, 2010.

YIN, R. K. Estudo de Caso: planejamento e métodos (4 ed.). Porto Alegre: Bookman, 2010. 